\title{
Survival Benefit with Gross Total Resection and Adjuvant Radiotherapy in Childhood Atypical Teratoid/Rhabdoid Tumors: Results of a Single-Center Cohort of 27 Cases
}

\author{
Ilkay ISIKAY ${ }^{1}$, Sahin HANALIOGLU², Ibrahim BASAR ${ }^{3}$, Firat NARIN ${ }^{4}$, Burcak BILGINER ${ }^{1}$ \\ ${ }^{1}$ Hacettepe University, Faculty of Medicine, Department of Neurosurgery, Ankara, Turkey \\ ${ }^{2}$ Health Sciences University, Diskapi Yildirim Beyazit Research and Training Hospital, Neurosrugery Clinic, Ankara, Turkey \\ ${ }^{3}$ Siirt State Hospital, Neurosurgery Clinic, Siirt, Turkey \\ ${ }^{4}$ Van Training and Research Hospital, Neurosurgery Clinic, Van, Turkey \\ This study has been presented at the Turkish Neurosurgical Society $31^{\text {st }}$ Scientific Congress between 29 March and 2 April 2017 at Antalya, Turkey.
}

Corresponding author: IIkay ISIKAY isikay@hacettepe.edu.tr

\section{ABSTRACT}

AIM: To share a single center experience with 27 atypical teratoid/rhabdoid tumor (AT/RT) cases, and to determine the effect of gross total tumor resection and other clinical characteristics on the overall survival rate of AT/RT.

MATERIAL and METHODS: We included 27 patients - with a histopathologically confirmed primary intracranial childhood AT/ RT - who were operated in our clinic between January 2000 and December 2017. Age, sex, tumor location, disseminated disease, the presence of hydrocephalus, symptom duration till diagnosis, the extent of resection, and adjuvant radiotherapy were evaluated for their influence on overall survival.

RESULTS: Median age at diagnosis for 27 patients was 19.1 months ( 7.2 months- 5 years). Gross total resection was possible in 13 (48.72\%) patients. Except for three patients who died of perioperative complications, all patients received chemotherapy and 11 received radiotherapy. In univariate analysis, male sex, older age at diagnosis ( $\geq 24$ months), gross total resection, and radiotherapy were associated with overall longer survival; however, radiotherapy remained the only significant parameter in multivariate analysis.

CONCLUSION: AT/RT is a rare and dreadful brain tumor that has low survival rates despite contemporary treatment. Radiotherapy seems to prolong survival; however, large-scale studies are needed to establish prognostic factors.

KEYWORDS: Brain neoplasms, Childhood, Observational study, Rhabdoid tumor

\section{INTRODUCTION}

$\Lambda$ typical teratoid/rhabdoid tumor (AT/RT) of childhood is a rare and aggressive tumor. Although it constitutes Jess than $2 \%$ of all pediatric CNS tumors, it is the most common malignant CNS tumor under one year of age $(13,24)$. Approximately $66 \%$ of cases presenting with this tumor are under two years of age, and AT/RT constitutes up to $20 \%$ of all childhood CNS tumors in patients younger than three years $(14,34)$.
Several first-phase $\mathrm{I} / \mathrm{II}$ trials are ongoing that employ agents designed explicitly for rhabdoid tumors targeting molecular defects. However, surgery, chemotherapy, and radiation are still the mainstay of treatment (13). Despite multimodal treatment including surgery followed by chemo-radiotherapy, less than $50 \%$ of cases remain alive at the end of the first year after diagnosis, and the five-year survival rate is as low as $28 \%$ (24). Influence of chemotherapy and radiation therapy on overall survival in this dreadful tumor is almost
Ilkay ISIKAY

Sahin HANALIOGLU

Ibrahim BASAR
(D) : 0000-0001-7790-4735

(D) : 0000-0003-4988-4938

(D) : 0000-0003-3674-4864
Firat NARIN

(1) : 0000-0002-5985-4460

Burcak BILGINER (D) : 0000-0001-9667-3709 
indisputable. There are a few single and multi-center series that explored the influence of prognostic factors on survival, and some of these looked at the effect of extent of resection $(2,8,10,16,19,31,33,35)$.

In this study, we aim to share our experience with singleinstitution 27 patients diagnosed with primary intracranial AT/ RT and determine the effect of gross total tumor resection and other clinical characteristics on overall survival of AT/RT.

\section{- MATERIAL and METHODS}

\section{Study Population}

In this study, we included 27 patients with a histopathologically confirmed primary intracranial AT/RT who were operated in our clinic between January 2000 and December 2017, and under 18 years of age at the time of diagnosis. Patient charts, discharge notes, radiology and pathology reports, and follow-up notes in our pediatric oncology clinic were analyzed in a retrospective manner. When the follow-up visits were conducted outside our clinic, telephonic interview was conducted to ascertain the final status of the patients.

\section{Clinical and Radiological Data}

Sex, age at the time of diagnosis, symptoms at admission, neurologic status, radiologic findings, the extent of resection, the presence of disseminated disease, and need for CSF diversion were recorded. All patients had preoperative cranial $\mathrm{MRI}$ at least consisting of three-planar T1 weighted, axial T2 weighted, and post-contrast axial T1 weighted images. A post-op MRI scan was performed in all patients within 48 hours postoperatively unless the patient was critically ill. Fluid-attenuated inversion recovery and diffusion-weighted images were available for patients who were operated after 2007. When MRI was not available, an early postoperative CT scan was performed to rule out surgical site hematoma and to document the extent of resection. Gross total resection (GTR) was defined as the absence of any visible residual tumor in the immediate postoperative MRI or CT scan. The extent of resection was regarded as either subtotal excision/biopsy if there was any sign of a radiologically-apparent residual tumor. Histopathological evaluation was based on the "The WHO Classification of Tumors of the Central Nervous System".

\section{Surgical Treatment, Adjuvant Therapy, and Survival}

Maximum safe resection was the goal of all surgical interventions. Postoperatively, all patients were followed up by a team of neurosurgeons, pediatric oncologists, and radiation oncologists. Adjuvant therapy consisted of various combinations of chemotherapeutic agents depending on the best available data at the time of treatment. For patients older than three years of age, radiotherapy was added to the treatment protocol. Overall survival was calculated as the duration between the time of diagnosis and time of death with censoring at the last follow-up for patients who were alive and for patients who were lost to follow-up. The exact date of out-of-hospital deaths was acquired using a web-based government service (www.obs.gov.tr).

\section{Statistical Analysis}

SPSS 23.0 (IBM Corp. Released 2015. IBM SPSS Statistics for Windows, Version 23.0. Armonk, NY: IBM Corp.) was used for statistical analysis. Means and standard deviations were calculated for parametric and normally distributed data. For non-parametric data or when data were not normally distributed, medians (range) were used whereas categorical data were presented as percentages. Survival analyses were performed using the Kaplan-Meier method. The log-rank test was used for comparison of subgroup outcomes. Cox proportional hazard model was used for multivariate analysis. A p-value lower than 0.05 was considered statistically significant.

\section{RESULTS}

\section{Demographic Data}

Clinical characteristics of patients are given in Table I. There were 27 patients (15 females, 12 males) in the study. The median age of patients at the time of diagnosis was 19.1 months (range 0-194.2). Only eight patients (29.6\%) were older than 36 months of age at admission and the distribution of children below and over 24 months of age was 14 and 13 patients respectively. Tumor location was supratentorial in 15 $(55.6 \%)$ and infratentorial in 12 (44.4\%) patients.

\section{Symptoms and Clinical Features}

One patient had a prenatal diagnosis of the tumor. Excluding this patient, the duration of signs and symptoms of patients ranged between seven days and six months (median 30 days). Signs and symptoms of patients are summarized in Table II. Hydrocephalus was the most common finding followed by ataxia, headache, and nausea/vomiting.

\section{Radiologic Characteristics}

The distribution of tumor location in the infratentorial compartment was as follows: tumor was seen occupying the fourth ventricle in three patients, main bulk of the tumor was situated in cerebellar hemispheres in four patients, and the cerebellopontine angle was occupied in three patients owing to tumors arising from middle cerebellar peduncle. One mesencephalic tumor was seen invading left crus cerebri. A midline cerebellar tumor extending to the pineal region through tentorial incisura was found in the infratentorial group. The tumor locations in the supratentorial compartment were as follows: four hypothalamic-chiasmatic tumors extending to the suprasellar cistern, one inside the third ventricle, six in cerebral hemispheres, one insular, one in pineal region, and two temporal intra-axial tumors extending extra-axially to invade meninges.

Pronounced contrast enhancement was noticed in $83.3 \%$ of cases (Figure 1A-F). Contrast enhancement was heterogeneous in most of the cases, and only a few showed homogeneous contrast enhancement. In three patients tumor showed slight contrast enhancement. In one patient, tumor in the cerebellopontine angle did not show enhancement at all after administration of contrast. In 11 cases, the signal 
intensity of the tumor was heterogeneous owing to mixed solid and cystic components.

Hydrocephalus was a prominent finding, particularly with large tumors. Five of the infratentorial tumors and four supratentorial tumors manifested with hydrocephalus at the time of diagnosis. Tumor location was fourth ventricle $(n=3)$, midline cerebellar, and left middle cerebellar peduncle for infratentorial lesions resulting in hydrocephalus. Regarding supratentorial tumors, those occupying suprasellar region $(n=2)$, pineal region, and left cerebral hemisphere caused hydrocephalus.

At the time of presentation, nodular or diffuse pial enhancement helped discern disseminated disease in $10(37.0 \%)$ patients (Figure 2A, B).

Table I: Clinical Characteristics of Study Cohort

\begin{tabular}{|c|c|c|c|c|c|c|c|c|c|c|}
\hline $\begin{array}{c}\text { Case } \\
\#\end{array}$ & Sex & $\begin{array}{c}\text { Age at } \\
\text { diagnosis } \\
\text { (months) }\end{array}$ & $\begin{array}{l}\text { Duration of } \\
\text { symptoms } \\
\text { (days) }\end{array}$ & $\begin{array}{l}\text { Tumor } \\
\text { location }\end{array}$ & GTR & $\begin{array}{l}\text { Adjuvant } \\
\text { Rdtx }\end{array}$ & $\begin{array}{l}\text { Follow-up } \\
\text { (months) }\end{array}$ & Complication & $\begin{array}{c}\text { HCP } \\
\text { Treated with } \\
\text { V/P shunt }\end{array}$ & Outcome \\
\hline 1 & $\mathrm{M}$ & 194.2 & 15 & $S$ & + & + & 50.0 & - & - & Dead \\
\hline 2 & $\mathrm{M}$ & 83.4 & 105 & 1 & + & + & 106.1 & Mutism & - & Dead \\
\hline 3 & $\mathrm{~F}$ & 116.1 & 30 & $S$ & + & + & 186.0 & - & - & Alive \\
\hline 4 & $\mathrm{~F}$ & 12.0 & 51 & I & + & - & 17.6 & CSF fistula & - & Dead \\
\hline 5 & M & 31.6 & 10 & I & - & - & 5.3 & - & - & Dead \\
\hline 6 & M & 40.5 & 7 & $S$ & + & + & 186.5 & - & - & Alive \\
\hline 7 & $\mathrm{~F}$ & 12.5 & 10 & $S$ & - & - & 3.7 & - & - & Dead \\
\hline 8 & M & 5.8 & 30 & 1 & - & + & 27.8 & CSF fistula & - & $\begin{array}{l}\text { Lost to } \\
\text { follow-up }\end{array}$ \\
\hline 9 & M & 18.5 & 180 & 1 & - & + & 7.6 & - & - & $\begin{array}{l}\text { Lost to } \\
\text { follow-up }\end{array}$ \\
\hline 10 & $\mathrm{~F}$ & 6.2 & 20 & I & + & - & 5.1 & - & - & Dead \\
\hline 11 & $\mathrm{~F}$ & 26.8 & 15 & 1 & - & - & 5.3 & - & - & Dead \\
\hline 12 & $\mathrm{~F}$ & 4.9 & 45 & $S$ & - & - & 0.1 & Periop mortality & - & Dead \\
\hline 13 & $\mathrm{~F}$ & 5.0 & 15 & $S$ & - & - & 4.9 & CSF fistula & + & Dead \\
\hline 14 & $\mathrm{~F}$ & 31.3 & 10 & I & - & - & 5.2 & Mutism & - & Dead \\
\hline 15 & M & 114.6 & 30 & $S$ & + & + & 57.2 & - & - & Alive \\
\hline 16 & M & 81.8 & 180 & S & - & + & 4.5 & - & - & Dead \\
\hline 17 & $\mathrm{~F}$ & 0.5 & 7 & 1 & - & - & 4.8 & CSF fistula & - & Dead \\
\hline 18 & $\mathrm{~F}$ & 41.8 & 150 & $S$ & + & + & 5.6 & - & + & Dead \\
\hline 19 & $\mathrm{~F}$ & 7.2 & 60 & 1 & + & - & 7.2 & - & + & Dead \\
\hline 20 & $\mathrm{~F}$ & 19.1 & 30 & $S$ & + & - & 8.5 & - & - & Dead \\
\hline 21 & $\mathrm{M}$ & 24.9 & 15 & $S$ & + & + & 15.3 & - & + & Dead \\
\hline 22 & $\mathrm{~F}$ & 8.9 & 60 & I & + & - & 0.2 & Periop mortality & - & Dead \\
\hline 23 & $\mathrm{M}$ & 9.3 & 10 & $S$ & - & - & 0.5 & Periop mortality & - & Dead \\
\hline 24 & $\mathrm{M}$ & 0.0 & Prenatal & $S$ & + & - & 5.8 & - & - & Dead \\
\hline 25 & $\mathrm{~F}$ & 8.2 & 15 & 1 & - & - & 7.1 & & + & Dead \\
\hline 26 & M & 37.0 & 150 & $S$ & - & + & 21.7 & - & + & Dead \\
\hline 27 & $\mathrm{~F}$ & 29.8 & 90 & I & - & - & 9.4 & Mutism & + & Dead \\
\hline
\end{tabular}

CSF: Cerebrospinal fluid, F: female, GTR: Gross total resection, HCP: Hydrocephalus, I: Infratentorial, M: Male, Rdtx: Radiotherapy, S: supratentorial, VIP: Ventriculo-peritoneal. 

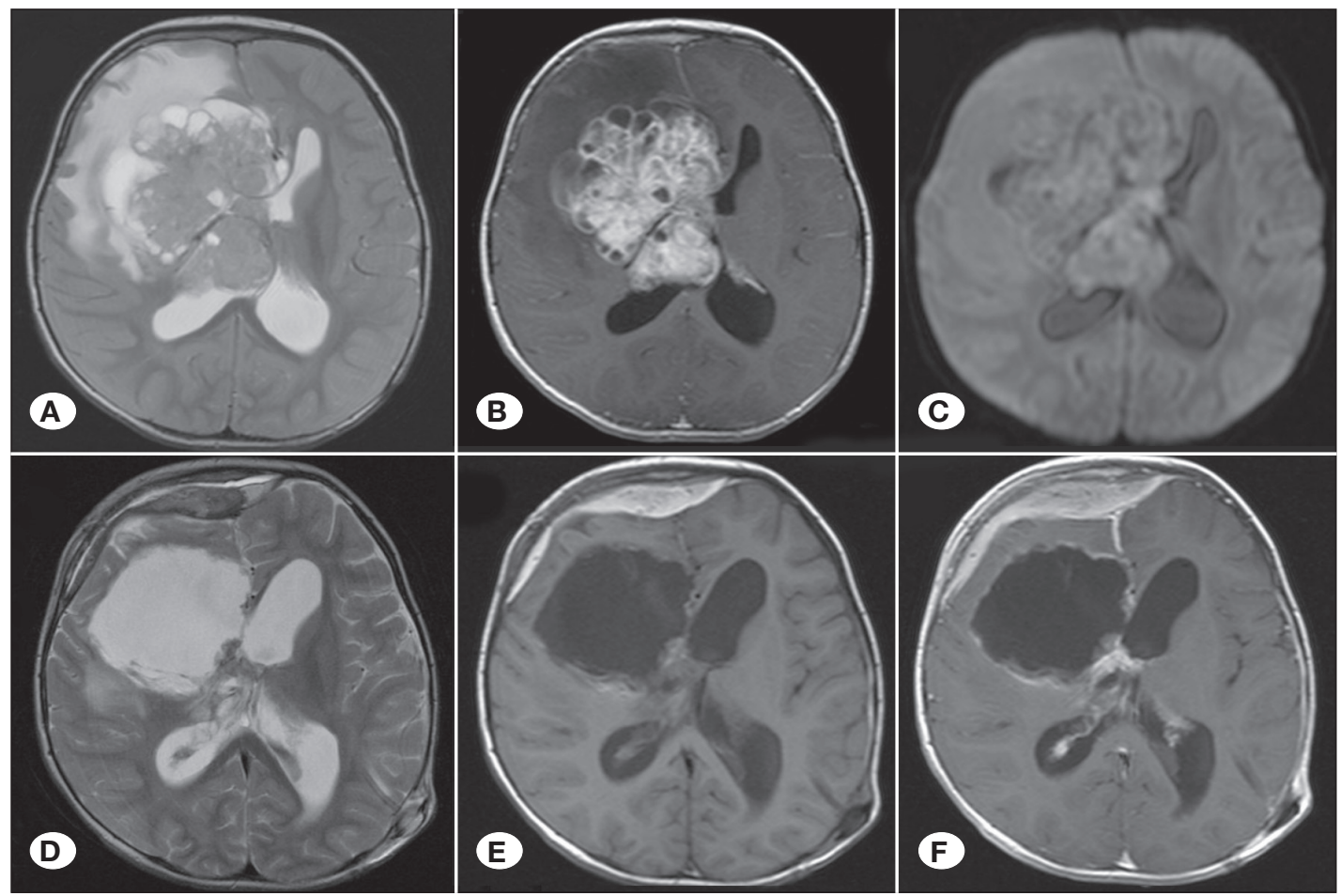

Figure 1: Preoperative and postoperative MRI scans of patient number 21 in Table 1. T2 weighted axial MR image shows a frontal intraparenchymal tumor. Tumor infiltrates right lateral ventricle and posterior part of third ventricle. There is significant peritumoral white matter edema in right frontal lobe which is demonstrated with hyper-intense signal changes (A). Tumor enhances heterogeneously after intravenous contrast agent administration. The solid central part is accompanied by numerous cystic structures on the periphery (B). Tumor shows high signal intensity on diffusion-weighted images, due to tumor's high nucleus-cytoplasm ratio and hypercellularity (C). Postoperative T2 weighted (D), pre-contrast T1 weighted (E) and T1 weighted contrast enhanced (F) axial MR images show gross total tumor excision. Ventriculoperitoneal shunt reservoir and part of ventricular catheter may also be seen on the left side in these images (D, E, F).

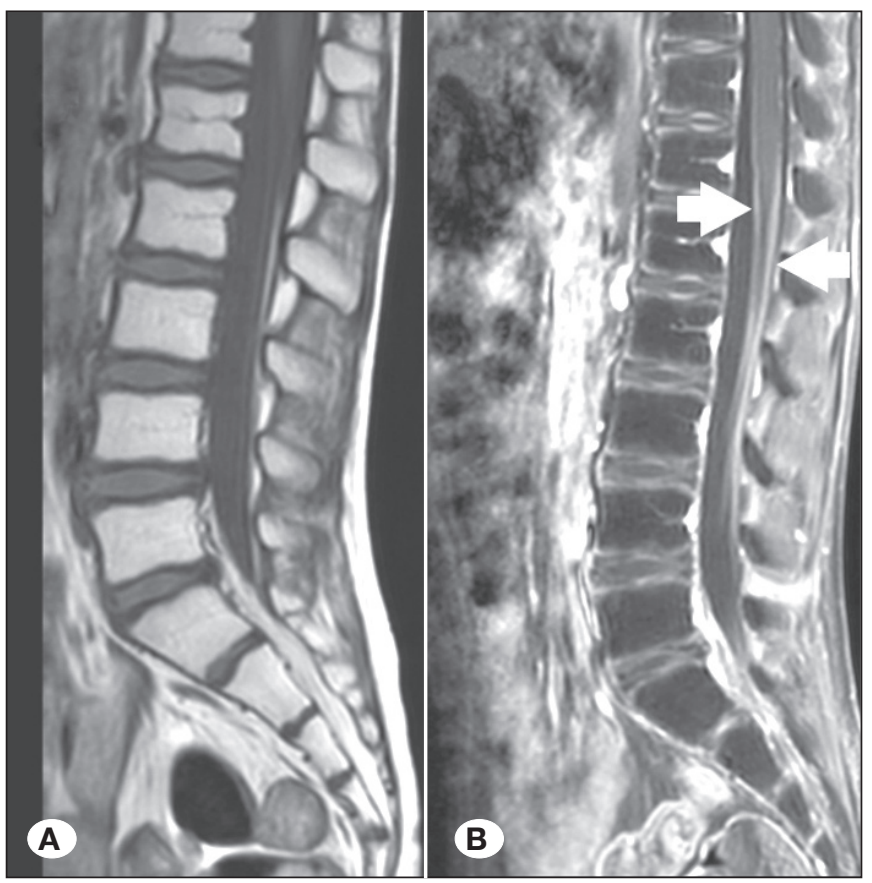

Figure 2: Pre-contrast T1 weighted (A) and post-contrast fat suppressed sagittal images (B). Arrows point to pial enhancement which indicates tumor seeding (B).

\section{Histopathologic Features}

On light microscopic examination, the tumors exhibited distinct cellular components. Rhabdoid cells were characterized with eccentrically located vesicular nuclei and clear, sometimes eosinophilic cytoplasm. Another component of the tumor was spindle-shaped mesenchymal cells along with small islands of primitive neuroectodermal foci. Cells showed pronounced pleomorphism and mitotic activity. Ki-67 index was high. Necrosis was a common finding in all specimens; however, histological evidence of focal calcification was observed in only $22.3 \%(n=6)$ of tumors. Definitive diagnosis was based on loss of INI1 expression in all tumor samples. Specimens showed immunoreactivity for vimentin in $74.1 \%$ of cases. Smooth muscle actin (SMA), epithelial membrane antigen (EMA), and glial fibrillary acidic protein immunoreactivity were observed in $70.4 \%, 66.7 \%$, and $29.6 \%$ of cases, respectively.

\section{Surgical Treatment, Follow-up, and Outcome}

GTR was achieved in 13 (48.2\%) patients. Overall median survival duration for 27 patients was 7.1 months. Permanent ventricul operitoneal shunt insertion was performed in seven out of the nine patients who had hydrocephalus preoperatively. Temporary CSF diversion was performed using external ventricular drainage catheter in the remaining two patients. Six $(22.2 \%)$ patients were operated twice due to either tumor 
Table II: Symptoms and Signs at Admission

\begin{tabular}{ll}
\hline Symptom and Sign & $\mathbf{n}$ \\
\hline Hydrocephalus & 9 \\
\hline Ataxia/difficulty in walking & 6 \\
\hline Headache & 6 \\
\hline Nausea/vomiting & 6 \\
\hline Eye deviation & 4 \\
\hline Hemiparesis/limb weakness & 3 \\
\hline Restlessness & 2 \\
\hline Somnolence & 2 \\
\hline Ptosis & 2 \\
\hline Torticollis & 2 \\
\hline Epileptic seizures & 2 \\
\hline Diabetes insipidus & 1 \\
\hline Diplopia & 1 \\
\hline Loss of head control & 1 \\
\hline
\end{tabular}

Table III: Clinical Characteristics and Median Survival Times

\begin{tabular}{|c|c|c|c|}
\hline Variables & Median survival (months) & $\begin{array}{c}\text { Univariate Analysis } \\
\mathbf{p}\end{array}$ & $\begin{array}{c}\text { Multivariate Analysis } \\
\text { p }\end{array}$ \\
\hline Sex & & 0.045 & 0.869 \\
\hline Male & 18.5 & & \\
\hline Female & 5.6 & & \\
\hline Age at diagnosis & & 0.039 & 0.524 \\
\hline$<24$ months & 5.4 & & \\
\hline$\geq 24$ months & 15.3 & & \\
\hline Duration of symptoms & & 0.111 & - \\
\hline$<1$ month & 5.3 & & \\
\hline$\geq 1$ month & 9.0 & & \\
\hline Location of tumor & & 0.865 & - \\
\hline Infratentorial & 7.2 & & \\
\hline Supratentorial & 5.8 & & \\
\hline Extent of resection & & 0.040 & 0.167 \\
\hline Subtotal resection/biopsy & 5.2 & & \\
\hline GTR & 15.3 & & \\
\hline Hydrocephalus & & 0.105 & - \\
\hline Absent & 9.0 & & \\
\hline Present & 5.1 & & \\
\hline Adjuvant radiotherapy & & 0.001 & 0.025 \\
\hline No & 5.3 & & \\
\hline Yes & 27.8 & & \\
\hline Disseminated disease & & 0.968 & - \\
\hline No & 7.1 & & \\
\hline Yes & 6.5 & & \\
\hline
\end{tabular}

recurrence $(n=4)$ or residual tumor $(n=2)$ identified on the postoperative radiologic study. Three patients (two with supratentorial and one with infratentorial tumor) died perioperatively owing to surgical complications, and immediate postoperative extubation was impossible in any of these three patients. Only one of the perioperative deaths was in the GTR group. Out of four patients who developed postoperative CSF fistula, two required wound revision, and the other two were managed conservatively. Three patients developed a brief period of cerebellar mutism after the resection of posterior fossa tumors possibly because ofa partial split of the inferior vermis. Postoperative chemotherapy regimen was initiated for all surviving patients. All the eight patients older than 36 months of age and an additional three patients who were younger at the time of diagnosis received adjuvant radiation therapy. Mean followup time for the 27 patients was 28.1 months.

Clinical characteristics, such as sex, patient age at the time of diagnosis, the location of the tumor, the extent of resection, adjuvant radiotherapy, duration of symptoms, the presence of disseminated disease, and hydrocephalus were assessed for their influence on overall survival. Two equal sized subgroups were formed by choosing 24 months as the cut-off value for 
patient age and 30 days as the cut-off value for the duration of symptoms. In univariate analysis, male sex, older patient age, gross total tumor resection, and administration of adjuvant radiotherapy were associated with improved survival (Table III). In multivariate Cox proportional hazards model with backward elimination for the prediction of overall survival, only adjuvant radiotherapy was shown to increase survival (Table III). Kaplan-Meier curve for the entire cohort and survival curves comparison for the subgroups are given in Figure 3.

At the end of the study period, three patients belonging to the gross total tumor resection and the adjuvant chemoradiotherapy group were still alive with the recorded follow-up time of $57.2,186.0$, and 186.5 months.

\section{DISCUSSION}

An atypical teratoid/rhabdoid tumor is a rare disease with unfavorable outcome most commonly seen in children, although few cases of adult AT/RT have also been reported (20). Patient age at the time of diagnosis ranges between 7.2 months and 5 years $(1,7,21,22,25,26,28)$; however, cases of in utero diagnosis have also been reported (4).

Intracranial location of AT/RT has been reported to be in the posterior fossa $(\sim 55 \%)$, in the supratentorial compartment $(\sim 40 \%)$, or pineal region $(\sim 5 \%)$ in many series $(9,30)$. When in the posterior fossa, the tumor may invade cerebellar tissue, block fourth ventricular outflow, or it may grow exophytically from cerebellar peduncles to occupy the cerebellopontine angle-found in $11.1 \%$ of cases in our series. The distribution of supratentorial and infratentorial tumor cases in our study was $56.4 \%$ and $44.4 \%$, respectively. Likewise, in a series of 15 AT/RT cases, Biswas et al. reported a higher number of supratentorial tumors (60\% vs. $40 \%)$ (4). Hilden et al. published results of therapy in 42 children enrolled in a registry wherein they reported $61.9 \%$ supratentorial location (16). Additionally, the general literature reveals that these tumors are predisposed to cerebellar fossa $(12,18)$.

Radiological findings of AT/RT are generally indistinguishable from PNET and medulloblastomas (11). Typical CT scan finding of $A T / R T$ is increased-density solid mass due to tumor's high cellular content that enhances heterogeneously after contrast administration. In the magnetic resonance (MR) era, the benefit of performing cranial CT is debatable; however, it can help in accelerating a definitive diagnosis. Typical MR scan presentations of AT/RT are hypointense signals on T1weighted images, hypo- or isointense signals on T2-weighted images, and heterogeneous contrast enhancement with areas of hemorrhage and necrosis (11). AT/RT is also characterized by restricted diffusion because of hypercellularity and neoplastic cells with high nuclear-to-cytoplasmic ratios and small extracellular spaces (21). Because these features are relatively typical for other tumors, such as PNET, medulloblastoma, and ependymoma, a definitive radiological diagnosis is often impossible. Most of the radiology reports in our study included AT/RT in the differential diagnosis and none identified AT/RT definitively.

Light microscopic characteristics of AT/RT include rhabdoid cells with eccentric round nuclei containing prominent nucleoli within a fibrillary or granular eosinophilic cytoplasm. There are sometimes small spindle-shaped rhabdoid cells with ovoid nuclei or large cells containing nuclei with wrinkled margins $(5,30)$. AT/RT is so called because of the varying number of PNET cells, malignant mesenchymal spindle-shaped cells, and cells with epithelial differentiation accompanying the rhabdoid cells (29). AT/RT tumors have previously been mistaken for PNET-medulloblastomas because of their similar histological features. Therefore, a careful immunohistochemical workup is warranted (3). Positive reactions to neural antibodies, such

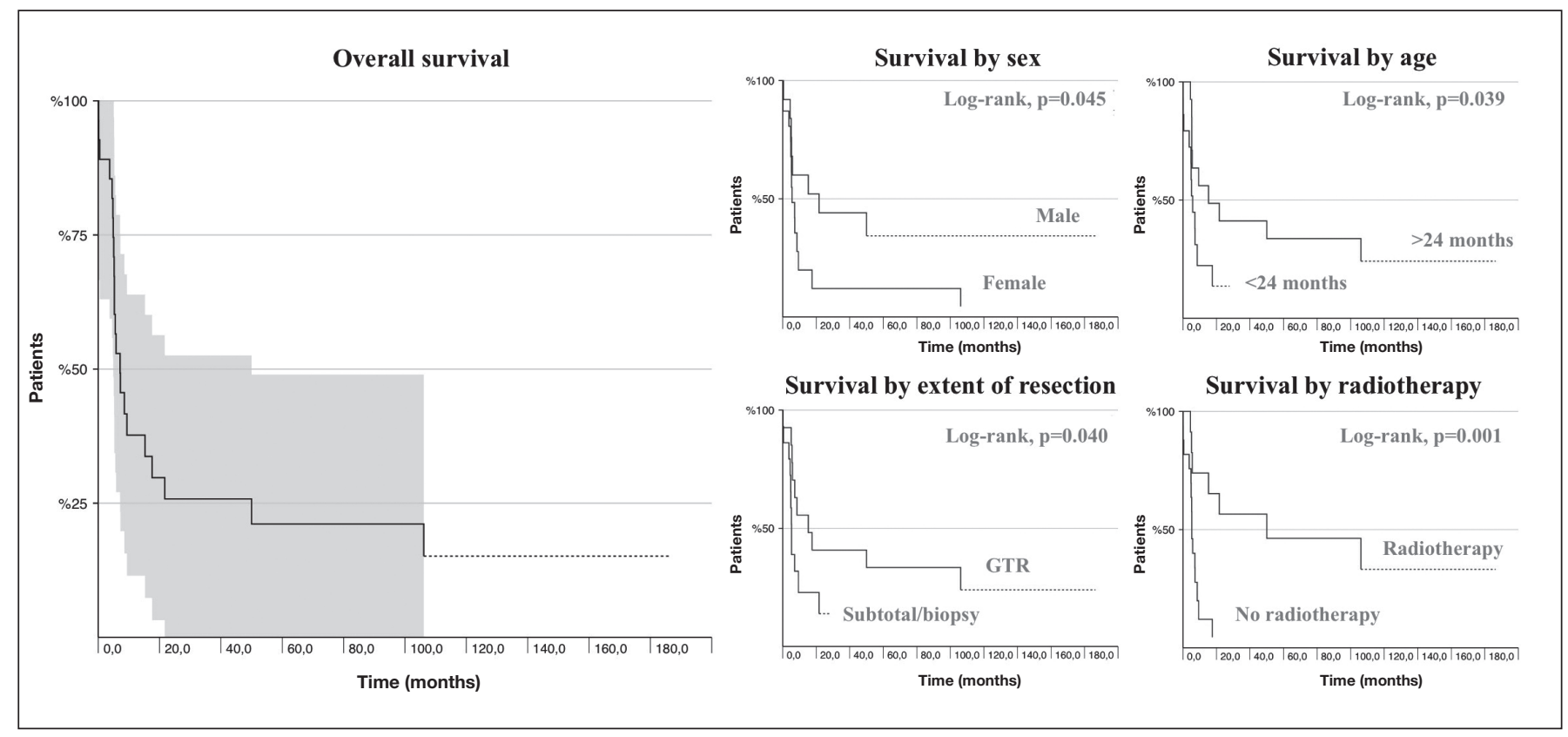

Figure 3: Kaplan-Meier curves for clinical characteristics (GTR: gross total resection). 
as neurofilament protein and glial fibrillary acid protein, can be exhibitedin both PNET and AT/RT. Nevertheless, rhabdoid cells in AT/RT typically express EMA, vimentin, and SMA-an identification maker that can differentiate it from PNET and germ cell tumors $(15,21)$. Our study observed EMA, SMA, and vimentin positivity in $66.7 \%, 70.4 \%$, and $74.1 \%$ of cases, and a definitive diagnosis was based on the loss of INI1 expression.

Several studies have explored the risk factors for short survival and attempted to relate the clinical characteristics (sex, age at the time of diagnosis, the extent of resection, the effect of radiotherapy and chemotherapy) with the disease outcome (Table IV).

Influence of gross total tumor resection on event-free survival and overall survival was first mentioned by Hilden et al. in 2004 (16), and followed by many others. In 2005, Tekautz et al. reported a marginal advantage of GTR in 31 patients from St. Jude Cancer Research Center (33). Additionally, Chi et al. emphasized the benefit of the extent of resection on eventfree survival and overall survival in a multi-institutional study of 20 patients (8). A recent 50-patient multi-institutional study pointed out that age, location, and presence of metastatic disease are not prognostic but suggested that GTR and high dose chemotherapy are favorable indicators (19).

Several single-center, multi-center, and registry studies have reported contradicting results regarding the effect of GTR on the outcome $(2,10,35)$. Interestingly, one of the biggest multicenter series assessing 361 AT/RT cases does not report an increased survival duration with GTR (12). However, the patient cohort of that study was extracted from a national cancer database and extent of resection was unknown for most cases $(64.0 \%)$ - probably why the influence of GTR was not considered.

In the present study, the extent of resection was a significant variable in univariate analysis but not in multivariate analysis.
Interestingly, studies that report the extent of resection as a prognostic factor either give results for only univariate analysis or the effect of GTR is no longer significant when adjusted for other prognostic factors. Therefore, our results are in parallel with general literature.

The effect of radiotherapy on overall survival for patients older than three years is possibly more evident. For instance, Chen et al. report a correlation between failure-free survival and total irradiation dose, the time interval between surgery and radiotherapy initiation, thus indicating that deferring the initiation of radiation therapy had adverse effects on patient outcome (7). Previous publications have demonstrated the neurocognitive complications owing to whole-brain aggressive large-field radiation given to infants (27). Nonetheless, some authors encourage performing more focused conformal radiotherapy for young children with localized AT/RT based on the increase in overall and event-free survival rates with radiation therapy (12). Fischer-Valuck et al. demonstrated, through a large cohort of AT/RT patients, an increasing rate of radiation therapy given to younger children. Per the study, the hazards analysis of overall survival revealed hazard ratio of being diagnosed in between 2009-2012 is 0.58 when compared to the reference group (patients diagnosed between 2004-2008). Authors relate the survival benefit to increased utilization of radiotherapy in patients 0-2 years of age during the 2009-2012 period. With a cut-off point of 24 months for patient age at the time of diagnosis, we demonstrated that older children survived longer when compared to younger. The reason for choosing 24 months as the cut-off point was: First, because of the way the cohort was divided into two equal subgroups. Second, several studies in the literature compared survival differences in patients younger and older than two years of age. The finding regarding survival duration for older children in our study also conforms to general literature $(12,35)$. As speculated by others, the unfavorable outcome

Table IV: Basic Clinical Characteristics and Their Impact on Survival According to Some Major Series in the Literature

\begin{tabular}{|c|c|c|c|c|c|c|c|c|}
\hline Author & $\begin{array}{c}\text { Number of } \\
\text { patients }\end{array}$ & Sex & Age & $\begin{array}{l}\text { Extent of } \\
\text { resection }\end{array}$ & $\begin{array}{l}\text { Tumor } \\
\text { location }\end{array}$ & $\begin{array}{l}\text { Metastatic } \\
\text { disease }\end{array}$ & $\begin{array}{l}\text { Complete } \\
\text { remission }\end{array}$ & $\begin{array}{c}\text { Radiation } \\
\text { therapy }\end{array}$ \\
\hline Chi et al., 2009 (8) & 20 & - & NS & Univariate & Univariate & NS & - & - \\
\hline $\begin{array}{l}\text { Dufour et al., } \\
2012(10)\end{array}$ & 58 & - & Multivariate & NS & NS & Multivariate & - & - \\
\hline $\begin{array}{l}\text { von Hoff et al., } \\
2011 \text { (35) }\end{array}$ & 56 & - & Multivariate & Univariate & Univariate & Univariate & Univariate & NS \\
\hline $\begin{array}{l}\text { Lafay-Cousin et al., } \\
2012(19)\end{array}$ & 50 & - & NS & Univariate & - & - & Univariate & NS \\
\hline $\begin{array}{l}\text { Buscariollo et al., } \\
2012 \text { (6) }\end{array}$ & 144 & NS & NS & NS & NS & Multivariate & - & Multivariate \\
\hline $\begin{array}{l}\text { Bartelheim et al., } \\
2016 \text { (2) }\end{array}$ & 31 & - & Univariate & NS & - & NS & Multivariate & Multivariate \\
\hline Present study & 27 & Univariate & Univariate & Univariate & NS & NS & - & Multivariate \\
\hline
\end{tabular}

NS: Not significant, Univariate: Variable significantly influences overall/progression free survival in univariate analysis, Multivariate: Variable significantly influences overall/progression free survival in multivariate analysis. 
in young patients might be partly because of limited use of radiotherapy - corroborated by the finding that when radiation therapy is given to patients under two years, their overall survival was similar to that of older children (12). Although the role of limited use of radiotherapy as a justification for the unfavorable outcome cannot be ignored, young age is associated with more aggressive behavior biologically.

Recently Johann et al. have identified three distinct molecular subgroups of AT/RT (17)-ATRT-TYR, ATRT-SHH, and ATRTMYC. Their findings support that although all three AT/RT types are characterized by the prototypic loss of expression of SMARCB1 or SMARCB4, the disease is heterogeneous with epigenetic differences. MRI characteristics of these three types, such as preferred tumor location, peritumoral edema, and contrast enhancement, have indeed been demonstrated; however, clinical differences in these subtypes are not apparent (23). This recent finding can probably explain the contradictions in risk factor identification for short survival and characteristics with favorable patient outcomes.

We herein assessed the overall survival of AT/RT cases related to various clinical features along with descriptive demographic and clinical information. Like several studies in the literature, our study has an analytical observational design (32), that diminishes its power. Another weakness in our study is the lack of progress-free survival or event-free survival rate; instead we could only give the overall survival rate. Unfortunately, insufficiency in collecting the data spanning over a considerable time resulted in this shortcoming. Despite the significant flaw, overall survival rates and survival rates for the subgroup of patients in our study compare well with the relevant literature. Unfortunately, there is no standardized treatment plan because of the rarity of AT/RT, and management strategies for this devastating disease are mainly individualized. This fact was reflected in our study as well wherein there was no established chemotherapy regimen. Therefore, it was not possible for us to evaluate the effects of different chemotherapeutics on survival.

\section{- CONCLUSION}

AT/RT is a rare and dreadful brain tumor. Even with contemporary medicine, the survival rate is low, though promising studies are underway. A single-center randomized controlled study design is impractical owing to the rarity of the tumor. Therefore, larger trials explicitly designed for AT/RT that incorporates new tumor subtypes are needed to establish standard management strategies. Until that time, studies with rather small sample sizes, like ours, may contribute to the establishment of meta-analyses.

\section{ACKNOWLEDGMENTS}

Preparation for publication of this article is partly supported by Turkish Neurosurgical Society.

\section{REFERENCES}

1. Al-Hussaini M, Swaidan M, Al-Jumaily U, Musharbash A: Central nervous system tumors in the first year of life: A clinical and pathologic experience from a single cancer center. Childs Nerv Syst 29:1883-1891, 2013

2. Bartelheim K, Nemes K, Seeringer A, Kerl K, Buechner J, Boos J, Graf N, Durken M, Gerss J, Hasselblatt M, Kortmann RD, Teichert von Luettichau I, Nagel I, Nygaard R, Oyen F, Quiroga E, Schlegel PG, Schmid I, Schneppenheim R, Siebert R, Solano-Paez P, Timmermann B, Warmuth-Metz M, Fruhwald MC: Improved 6-year overall survival in AT/RT - results of the registry study Rhabdoid 2007. Cancer Med 5:1765-1775, 2016

3. Biegel JA, Fogelgren B, Zhou JY, James CD, Janss AJ, Allen JC, Zagzag D, Raffel C, Rorke LB: Mutations of the INI1 rhabdoid tumor suppressor gene in medulloblastomas and primitive neuroectodermal tumors of the central nervous system. Clin Cancer Res 6:2759-2763, 2000

4. Biswas A, Julka PK, Bakhshi S, Suri A, Rath GK: Intracranial atypical teratoid rhabdoid tumor: Current management and a single institute experience of 15 patients from North India. Acta Neurochir (Wien) 157:589-596, 2015

5. Burger PC, Yu IT, Tihan T, Friedman HS, Strother DR, Kepner JL, Duffner PK, Kun LE, Perlman EJ: Atypical teratoid/ rhabdoid tumor of the central nervous system: A highly malignant tumor of infancy and childhood frequently mistaken for medulloblastoma: A Pediatric Oncology Group study. Am J Surg Pathol 22:1083-1092, 1998

6. Buscariollo DL, Park HS, Roberts KB, Yu JB: Survival outcomes in atypical teratoid rhabdoid tumor for patients undergoing radiotherapy in a Surveillance, Epidemiology, and End Results analysis. Cancer 118(17):4212-4219, 2012

7. Chen YW, Wong TT, Ho DM, Huang PI, Chang KP, Shiau CY, Yen SH: Impact of radiotherapy for pediatric CNS atypical teratoid/rhabdoid tumor (single institute experience). Int $\mathrm{J}$ Radiat Oncol Biol Phys 64:1038-1043, 2006

8. Chi SN, Zimmerman MA, Yao X, Cohen KJ, Burger P, Biegel JA, Rorke-Adams LB, Fisher MJ, Janss A, Mazewski C, Goldman S, Manley PE, Bowers DC, Bendel A, Rubin J, Turner CD, Marcus KJ, Goumnerova L, Ullrich NJ, Kieran MW: Intensive multimodality treatment for children with newly diagnosed CNS atypical teratoid rhabdoid tumor. J Clin Oncol 27:385-389, 2009

9. Dang T, Vassilyadi M, Michaud J, Jimenez C, Ventureyra EC: Atypical teratoid/rhabdoid tumors. Childs Nerv Syst 19:244248, 2003

10. Dufour C, Beaugrand A, Le Deley MC, Bourdeaut F, Andre N, Leblond P, Bertozzi Al, Frappaz D, Rialland X, Fouyssac F, Edan C, Grill J, Quidot M, Varlet P: Clinicopathologic prognostic factors in childhood atypical teratoid and rhabdoid tumor of the central nervous system: A multicenter study. Cancer 118:3812-3821, 2012

11. Fenton LZ, Foreman NK: Atypical teratoid/rhabdoid tumor of the central nervous system in children: An atypical series and review. Pediatr Radiol 33:554-558, 2003 
12. Fischer-Valuck BW, Chen I, Srivastava AJ, Floberg JM, Rao YJ, King AA, Shinohara ET, Perkins SM: Assessment of the treatment approach and survival outcomes in a modern cohort of patients with atypical teratoid rhabdoid tumors using the National Cancer Database. Cancer 123:682-687, 2017

13. Fruhwald MC, Biegel JA, Bourdeaut F, Roberts CW, Chi SN: Atypical teratoid/rhabdoid tumors-current concepts, advances in biology, and potential future therapies. Neuro Oncol 18:764-778, 2016

14. Ginn KF, Gajjar A: Atypical teratoid rhabdoid tumor: Current therapy and future directions. Front Oncol 2:114, 2012

15. Guner G, Onder S, Soylemezoglu F: Cytomorphological features of atypical teratoid/rhabdoid tumor: An account of 12 years' experience. Diagn Cytopathol 42:856-862, 2014

16. Hilden JM, Meerbaum S, Burger P, Finlay J, Janss A, Scheithauer BW, Walter AW, Rorke LB, Biegel JA: Central nervous system atypical teratoid/rhabdoid tumor: Results of therapy in children enrolled in a registry. J Clin Oncol 22:28772884, 2004

17. Johann PD, Erkek S, Zapatka M, Kerl K, Buchhalter I, Hovestadt V, Jones DTW, Sturm D, Hermann C, Segura Wang M, Korshunov A, Rhyzova M, Grobner S, Brabetz S, Chavez L, Bens S, Groschel S, Kratochwil F, Wittmann A, Sieber L, Georg C, Wolf S, Beck K, Oyen F, Capper D, van Sluis P, Volckmann R, Koster J, Versteeg R, von Deimling A, Milde T, Witt O, Kulozik AE, Ebinger M, Shalaby T, Grotzer M, Sumerauer D, Zamecnik J, Mora J, Jabado N, Taylor MD, Huang A, Aronica E, Bertoni A, Radlwimmer B, Pietsch T, Schuller U, Schneppenheim R, Northcott PA, Korbel JO, Siebert R, Fruhwald MC, Lichter P, Eils R, Gajjar A, Hasselblatt M, Pfister SM, Kool M: Atypical teratoid/rhabdoid tumors are comprised of three epigenetic subgroups with distinct enhancer landscapes. Cancer Cell 29:379-393, 2016

18. Kirkman MA, Hayward R, Phipps K, Aquilina K: Outcomes in children with central nervous system tumors disseminated at presentation: A large single-center experience. Childs Nerv Syst 2018 (Epub ahead of print)

19. Lafay-Cousin L, Hawkins C, Carret AS, Johnston D, Zelcer S, Wilson B, Jabado N, Scheinemann K, Eisenstat D, Fryer C, Fleming A, Mpofu C, Larouche V, Strother D, Bouffet E, Huang A: Central nervous system atypical teratoid rhabdoid tumours: The Canadian Paediatric Brain Tumour Consortium experience. Eur J Cancer 48:353-359, 2012

20. Makuria AT, Rushing EJ, McGrail KM, Hartmann DP, Azumi $\mathrm{N}$, Ozdemirli M: Atypical teratoid rhabdoid tumor (AT/RT) in adults: Review of four cases. J Neurooncol 88:321-330, 2008

21. Meyers SP, Khademian ZP, Biegel JA, Chuang SH, Korones DN, Zimmerman RA: Primary intracranial atypical teratoid/ rhabdoid tumors of infancy and childhood: MRI features and patient outcomes. AJNR Am J Neuroradiol 27:962-971, 2006

22. Nicolaides T, Tihan T, Horn B, Biegel J, Prados M, Banerjee A: High-dose chemotherapy and autologous stem cell rescue for atypical teratoid/rhabdoid tumor of the central nervous system. J Neurooncol 98:117-123, 2010

23. Nowak J, Nemes K, Hohm A, Vandergrift LA, Hasselblatt M, Johann PD, Kool M, Fruhwald MC, Warmuth-Metz M: Magnetic resonance imaging surrogates of molecular subgroups in atypical teratoid/rhabdoid tumor. Neuro Oncol 20:1672-1679, 2018
24. Ostrom QT, Chen Y, P MdB, Ondracek A, Farah P, Gittleman H, Wolinsky Y, Kruchko C, Cohen ML, Brat DJ, BarnholtzSloan JS: The descriptive epidemiology of atypical teratoid/ rhabdoid tumors in the United States, 2001-2010. Neuro Oncol 16:1392-1399, 2014

25. Partap S, Murphy PA, Vogel H, Barnes PD, Edwards MS, Fisher PG: Liposomal cytarabine for central nervous system embryonal tumors in children and young adults. J Neurooncol 103:561-566, 2011

26. Pinto EM, Hamideh D, Bahrami A, Orr BA, Lin T, Pounds $S$, Zambetti GP, Pappo AS, Gajjar A, Agnihotri S, Broniscer A: Malignant rhabdoid tumors originating within and outside the central nervous system are clinically and molecularly heterogeneous. Acta Neuropathol 136:315-326, 2018

27. Radcliffe J, Bunin GR, Sutton LN, Goldwein JW, Phillips PC: Cognitive deficits in long-term survivors of childhood medulloblastoma and other noncortical tumors: Agedependent effects of whole brain radiation. Int J Dev Neurosci 12:327-334, 1994

28. Ren YM, Wu X, You C, Zhang YK, Li Q, Ju Y: Multimodal treatments combined with gamma knife surgery for primary atypical teratoid/rhabdoid tumor of the central nervous system: A single-institute experience of 18 patients. Childs Nerv Syst 34:627-638, 2018

29. Rorke LB, Packer R, Biegel J: Central nervous system atypical teratoid/rhabdoid tumors of infancy and childhood. J Neurooncol 24:21-28, 1995

30. Rorke LB, Packer RJ, Biegel JA: Central nervous system atypical teratoid/rhabdoid tumors of infancy and childhood: Definition of an entity. J Neurosurg 85:56-65, 1996

31. Slavc I, Chocholous M, Leiss U, Haberler C, Peyrl A, Azizi AA, Dieckmann K, Woehrer A, Peters C, Widhalm G, Dorfer C, Czech T: Atypical teratoid rhabdoid tumor: Improved long-term survival with an intensive multimodal therapy and delayed radiotherapy. The Medical University of Vienna Experience 1992-2012. Cancer Med 3:91-100, 2014

32. Sut N: Study designs in medicine. Balkan Med J 31:273-277, 2014

33. Tekautz TM, Fuller CE, Blaney S, Fouladi M, Broniscer A, Merchant TE, Krasin M, Dalton J, Hale G, Kun LE, Wallace D, Gilbertson RJ, Gajjar A: Atypical teratoid/rhabdoid tumors (ATRT): Improved survival in children 3 years of age and older with radiation therapy and high-dose alkylator-based chemotherapy. J Clin Oncol 23:1491-1499, 2005

34. Thatikunta M, Mutchnick I, Elster J, Thompson MP, Huang MA, Spalding AC, Moriarty T: Neoadjuvant chemotherapy for atypical teratoid rhabdoid tumors: Case report. J Neurosurg Pediatr 19:546-552, 2017

35. von Hoff $\mathrm{K}$, Hinkes $\mathrm{B}$, Dannenmann-Stern $\mathrm{E}$, von Bueren AO, Warmuth-Metz M, Soerensen N, Emser A, Zwiener I, Schlegel PG, Kuehl J, Fruhwald MC, Kortmann RD, Pietsch T, Rutkowski S: Frequency, risk-factors and survival of children with atypical teratoid rhabdoid tumors (AT/RT) of the CNS diagnosed between 1988 and 2004, and registered to the German HIT database. Pediatr Blood Cancer 57:978-985, 2011 